\title{
No scope for complacency: time to improve healthcare for older people
}

\author{
Claire Hilton ${ }^{1}$ \\ The Psychiatrist (2012), 36, 441-443, doi: 10.1192/pb.bp.111.037267 \\ ${ }^{1}$ Central and North West London \\ NHS Foundation Trust \\ Correspondence to Claire Hilton \\ (claire.hilton@nhs.net) \\ First received 3 Oct 2011, final revision \\ 14 May 2012, accepted 18 Jun 2012 \\ Summary The Equality Act 2010 should prevent age discrimination in the provision \\ of healthcare and other services in the UK. The Royal College of Psychiatrists' Faculty \\ of the Psychiatry of Old Age and General \& Community Psychiatry Faculty have \\ offered constructive guidance to help achieve this. However, there are pitfalls. First, \\ legislation does not guarantee enforcement. Second, discrimination in the form of \\ persisting negative attitudes of society towards older people and their ability to \\ benefit from health interventions is associated with a deficit in funding old age \\ services that has accumulated gradually during the 60 years of the National Health \\ Service. These difficulties will need to be overcome to achieve effective \\ implementation of the Act.
}

Declaration of interest None.
The guidance on age equality from the Royal College of Psychiatrists' Faculty of the Psychiatry of Old Age and General \& Community Psychiatry Faculty ${ }^{1}$ is a breath of fresh air. It explores the implications of the Equality Act 2010. Under the Act, from April 2012 healthcare and other services in the UK must not discriminate by age and must be appropriate to the age of the service users. This is not the same as making services age inclusive. Equity of provision does not mean treating everyone the same, but rather recognising that different needs require different provision, distributed fairly. For example, putting older people with functional disorders on all-age wards where physical frailty, confusion or coexisting physical illness puts them at a disadvantage is unacceptable, ${ }^{2}$ as is inadequate training of staff working with them. Some people develop physiological and pathological changes usually associated with old age before the customary arbitrary dividing line of 65 years, others much later. Using a fixed chronological age cut-off for services in healthcare may be construed as ageist under the Act. A fixed age for accessing services also risks promoting ageism, by encouraging definitions of old age based on political and economic models rather than medically relevant ones. Flexibility to meet needs is essential, but there is then the risk that people falling into the 'grey areas' may be declared nobody's responsibility. No style of service provision is without its drawbacks.

\section{Tackling age discrimination}

Some services for older people have changed their referral criteria to emphasise clinically based parameters, to ensure that service delivery is best tailored to the patient's needs and least likely to be intrinsically ageist. However, the shape of an ideal service for older people is still open to debate. New service designs need further evaluation, but it is vital that they encourage and provide skills to treat functional and organic disorders in the presence of other illness and physical frailty. That breadth of approach has long been a valued characteristic of successful older people's services. Discarding what works well may also be ageist if it leaves a sector of the community without dedicated, needs-appropriate services.

Clinicians are not going to openly admit to ageism, but ageism, possibly unintentional, is deeply embedded in healthcare. A survey by the British Geriatrics Society and Age UK concluded that the National Health Service (NHS) is institutionally ageist. ${ }^{3}$ Ageism includes underestimating older people's ability to benefit from interventions, for both mental and physical illness. The latter was highlighted in a recent report about under-treating older people with cancer on the basis of chronological age rather than according to their overall health and fitness and likelihood of benefiting from treatment. ${ }^{4}$

The route to achieving non-discriminatory services is carefully outlined in the College statement. ${ }^{1}$ However, a number of pitfalls lie in our path and we must not be complacent.

\section{Law might not be enough}

Legislation alone does not guarantee enforcement. The NHS itself is enshrined in law by the National Health Service Act 1946. It was meant to be universal and provide for all age groups according to need. Laws to prevent discrimination on the grounds of disability, sexual orientation, gender, race and religion are still not fully implemented. Interpreting the law depends on the culture, expectations and understanding of society, not just legal matters. Society includes the 
medical profession, and politicians, policy makers and local healthcare commissioners designing services.

Arguments that higher numbers of older people relative to those of working age who support them will make social and welfare costs 'so great as to result in a lowering of the national standard of living, ${ }^{5}$ have been reiterated over decades. It has not happened. Current commentators doubt whether it ever will. ${ }^{6}$ There appears to be a fear of uncontrollable cost which has undermined levels of investment. An 'invest to save' model of older people's services has not been attempted. Rather than reducing initial costs, evidence has shown that investing in highquality new services can ultimately result in lower healthcare costs for older people. The Rapid Assessment Interface and Discharge (RAID) model of acute liaison hospital services ${ }^{7}$ and the Gnosall project for dementia care $^{8}$ are good examples. However, attitudes may undermine true equity when planning services. Health service commissioners might have little clinical experience of working with older people, and might not listen to clinicians. If decisions about service development are based on poor understanding of the illnesses experienced, or unwarranted negative perceptions of the potential for health improvement in old age, that is discrimination.

We need to listen to the optimists about the ageing society. ${ }^{9}$ Otherwise, debates about funding are likely to continue, at least partly because of ageism, and despite the Equality Act.

\section{The ' $E 2$ billion gap'}

The College's guidance on the Equality Act points to an incredible $£ 2$ billion gap in the funding of health services between older and younger adults. ${ }^{1}$ This has accumulated over many years.

Negative attitudes towards older people have contributed to relegating them to second place in healthcare provision. This preceded the NHS, but was explicit in the planning of the welfare state when Sir William Beveridge stated in 1942:

'It is dangerous to be in any way lavish to old age, until adequate provision has been assured for all other vital needs, such as the prevention of disease and the adequate nutrition of the young.,10

Fears at a time of high infant mortality and declining birth rate may have influenced that stance. But it also seems relevant to ongoing reluctance to provide age-appropriate services.

In 1947, the British Medical Association (BMA) committee on the care and treatment of the elderly and infirm commented about delays in the provision of services:

'Owing to the present restrictions on building construction and the shortages of trained staff, progress in achieving an improved medical service for the elderly will inevitably be slow. Many years must pass before any scheme . . can be brought fully into operation throughout the country. ${ }^{\text {in }}$

In 1956, a government-appointed committee reported on the cost of the NHS. It warned against under-resourcing older people's services:

'[T]he health authorities concerned should make sure that the needs of the aged are given their due priority in the allocation of additional resources and are not overlooked amid the pressure of other competing needs. ${ }^{12}$

Providing additional resources for old age was regarded as necessary, affordable and appropriate, but it was not forthcoming.

In the 1970s, health economist Nick Bosanquet reiterated the need to prioritise older people and prophesised:

'For the psycho-geriatric service a special financial incentive is needed. Health authorities should be asked to submit plans and they should be financed by a special earmarked allocation of funds. Otherwise the DHSS [Department of Health and Social Security] will very probably be re-issuing the same document in 1991 as it issued in 1959 and $1972 .^{\text {'13 }}$

The mental health charity Mind urged the government in 1979 'to introduce legislation compelling social services departments to provide an early assessment and intervention service.' ${ }^{14}$ That never happened. It is, however, reminiscent, 30 years later, of the National Dementia Strategy which aimed to achieve 'early diagnosis and intervention'. However, the Strategy unfortunately also stated that, 'There is no expectation ... that all areas will necessarily be able to implement the strategy within 5 years' ${ }^{15}$ Now, over 3 years into that 5 -year period, despite improvements in some places, elsewhere little has been achieved. Clinically sound, well-intentioned objectives have been tempered by the laissez-faire acceptability of delays in implementation, as feared by Mind, and all too similar to the BMA statement in 1947.

Providing adequate mental health services for older people may need to be made obligatory; giving providers discretion has not worked in the past. The Commissioning for Quality and Innovation (CQUIN) payment framework giving financial rewards for implementing clinical innovations may have that effect; the national dementia CQUIN to identify dementia in older people admitted to general hospitals may be a step in the right direction. ${ }^{16}$ However, the alarm has been raised by some geriatricians doubtful whether service capacity is sufficient for following up those identified. Nevertheless, the CQUIN is a welcome first step.

In 2009, there was a 24 -fold variation in activity between the highest and lowest performing primary care trusts for provision of dementia services. ${ }^{6}$ Age discrimination and the 'postcode lottery' both need to be addressed. The Faculty of the Psychiatry of Old Age and its predecessors have repeatedly tried to improve this state of affairs. Collaboration with other organisations such as Alzheimer's Society has helped, but old age service advocates are fighting widespread prejudices of society and have not yet achieved their goals. In March 2012, we heard the Prime Minister declare that dementia care is a 'national crisis'; once more deficits are acknowledged, but will they be remedied ? $^{17}$ Is this rhetoric, with action impeded by ageism?

Today, with the unfavourable economic climate, many might be tempted to reiterate the statement by the Ministry of Health in 1950 about proposals for better services for 'mental infirmity' in old age: 'It is recognised that the present conditions of financial stringency limit opportunities for action'. ${ }^{18}$ Repeatedly putting older people to the end of the queue is discriminatory and has 
not worked; the crisis remains. The Equality Act may provide opportunities to argue for and implement ageappropriate schemes on a par with those for younger people, and result in better health and cost savings.

\section{We cannot afford complacency}

We have a moral and ethical obligation to support people who are dependent because of age, illness or disability. The Equality Act should help us achieve that. It will be disastrous if the Act is allowed to join a catalogue of other ineffective legislation and powerless Department of Health proposals. The Act is well intentioned and idealistic with respect to older people. We need to grasp the opportunity it gives us and ensure it succeeds.

\section{Acknowledgements}

Thanks to Professors Tom Arie and Dave Jolley for their comments.

\section{About the author}

Claire Hilton is a consultant psychiatrist, Older People and Health Ageing Directorate, Central and North West London NHS Foundation Trust, Harrow, London, UK.

\section{References}

1 Faculty of the Psychiatry of Old Age, General and Community Psychiatry Faculty. The Equality Act 2010 and Adult Mental Health Services: Achieving Non-Discriminatory Age-Appropriate Services (Occasional Paper OP82). Royal College of Psychiatrists, 2011.
2 Faculty of the Psychiatry of Old Age. In-Patient Care for Older People within Mental Health Services (Faculty Report FR/OA/1). Royal College of Psychiatrists, 2011.

3 Help the Aged. Half of doctors say NHS is ageist. BGS News 2009; March: 8.

4 Macmillan Cancer Support. The Age Old Excuse: The Under Treatment of Older Cancer Patients. Macmillan Cancer Support, 2012.

5 Rowntree BS. Old People: Report of a Survey Committee on the Problems of Ageing and the Care of Old People. Oxford University Press, 1947.

6 Spence D. Baby boomers go bust. BMJ 2012; 344: e2191.

7 Parsonage M, Fossey M. Economic Evaluation of a Liaison Psychiatry Service. Centre for Mental Health, 2011.

8 Greaves N, Greaves I. The Gnosall project: setting new benchmarks for dementia care. J Care Serv Manag 2011; 5: 49-52.

9 WRVS. Gold Age Pensioners: Valuing the Socio-Economic Contributions of Older People in the UK. WRVS, 2011 (http://www.wrvs.org.uk/ourimpact/reports-and-reviews/gold-age-pensioners).

10 Beveridge W. Social Insurance and Allied Services (Cmnd 6404). HMSO, 1942.

11 British Medical Association. The Care and Treatment of the Elderly and Infirm. BMA, 1947

12 Ministry of Health. Report of the Committee of Enquiry into the Cost of the National Health Service (Cmnd 9663). HMSO, 1956.

13 Bosanquet N. New Deal for the Elderly. Fabian Society, 1975.

14 Lancet. Mental health of elderly people. 1979; i: 395.

15 Department of Health. Living Well with Dementia: A National Dementia Strategy. Department of Health, 2009.

16 Burns A. Introducing the national dementia CQUIN. Department of Health, 2012 (http://dementia.dh.gov.uk/introducing-the-nationaldementia-cqin/).

17 BBC News. Dementia: PM promises push to tackle 'national crisis'. 26 March 2012 (http://www.bbc.co.uk/news/health-17507678).

18 Ministry of Health. Care of the Aged Suffering from Mental Infirmity. HMC (50)25, 1950. 